\title{
The Intrinsic and Extrinsic Motivation towards Physical Activity among Malaysian Technical University (UTeM) Students
}

\author{
M. F. Abdullah", , A. M. Pilus², M. R. A. Razak ${ }^{1}$, A. Y. A. Bakar ${ }^{1, *}$, M. N. Nazarudin ${ }^{3}$ \\ ${ }^{1}$ Faculty of Education, Universiti Kebangsaan Malaysia, 43600 Bangi, Selangor, Malaysia \\ ${ }^{2}$ Institute of Technology Management and Entrepreneurship, Universiti Teknikal Malaysia Melaka, 76100 Melaka, Malaysia \\ ${ }^{3}$ Faculty of Psychology and Education, Universiti Malaysia Sabah, 88400 Kota Kinabalu, Sabah, Malaysia
}

Received January 24, 2021; Revised March 15, 2021; Accepted March 30, 2021

\section{Cite This Paper in the following Citation Styles}

(a): [1] M. F. Abdullah, A. M. Pilus, M. R. A. Razak, A. Y. A. Bakar, M. N. Nazarudin, "The Intrinsic and Extrinsic Motivation towards Physical Activity among Malaysian Technical University (UTeM) Students," International Journal of Human Movement and Sports Sciences, Vol. 9, No. 2, pp. 375 - 382, 2021. DOI: 10.13189/saj.2021.090227.

(b): M. F. Abdullah, A. M. Pilus, M. R. A. Razak, A. Y. A. Bakar, M. N. Nazarudin(2021). The Intrinsic and Extrinsic Motivation towards Physical Activity among Malaysian Technical University (UTeM) Students. International Journal of Human Movement and Sports Sciences, 9(2), 375 - 382. DOI: 10.13189/saj.2021.090227.

Copyright $@ 2021$ by authors, all rights reserved. Authors agree that this article remains permanently open access under the terms of the Creative Commons Attribution License 4.0 International License

\begin{abstract}
This study explores the inherent and external factors which influence university students' involvement in physical activity. As the key respondents were reacting to the adapted Exercise Reward Inventory and Participation Motivation questionnaire, 400 students comprising 200 males and 200 females were sampled. It shows that health and fitness $(M=4.37)$ are the intrinsic highest mean value variables, whereas peers and friends $(\mathrm{M}=3.97)$ are factors for extrinsic variables. There are substantial differences in the presence of inherent health and fitness motives between gender and physical influences $(\mathrm{t}=-6.51, \mathrm{p}<1.05)(\mathrm{t}=$ $5.05, \mathrm{p}<0.05$ ). Only in the family did there appear to be substantial sex variations in extrinsic motivation $(t=6.98$, $\mathrm{p}<0.05)$. There were only substantial variations of sex in relation to external motivation in the family $(\mathrm{t}=6.98, \mathrm{p}<$ $0.05)$. Lastly, the most contributing factors to physical activity are the inherent motivational and extrinsic motivational factors (the position of the university). University should emphasise the opportunity to promote physical activity among more students by encouraging safer cultural activities between men and women. This study is also important for the physical and spiritual growth of healthy students. This experience shows that the most successful way, particularly for students, is to make the next generation safe and energy efficient.
\end{abstract}

Keywords Motivation, Physical Activity, Technical
University Students, Malaysia

\section{Introduction}

Physical exercise is very important as it can take care of the health and the person away from dangerous diseases, such as cardiovascular diseases, high blood pressure, diabetes and other conditions. Moreover, regular activity will support the person as well as battle a variety of physical and mental health diseases and conditions [1]. Reduced anxiety and depression levels, as well as increased emotional activity and exercise in a more optimistic direction, may enhance mental wellbeing, including cognitive performance. [2]. This shows that physical exercise at the university will improve the student's physical and mental success.

The current rate of human disease is linked to a delicate lifestyle. There is proof that adopting unhealthy lifestyles is one of the top ten deaths caused by exercise is more than two million [3]. The exclusion of adequate preparation results in high disease levels raise the risk of heart illness in the elderly.

At least to a certain extent, the decline in physical exercise has contributed to adult participation because their 
physical exercise has no major impact on their health. All groups that are important to the well-being and well-being of people should be inspired. The degree of self-image, encouragement of peers and parents' support are typically the most important factors affecting the participation of students in physical activity. However, it has become an important concern for the well-being of people, including teenagers and adult individuals in this era of physical activity. Health experts have recognised the link between physical activity and health as a way to avoid many dangerous illnesses [4].

A range of benefits are derived from physical activity research, including reduced risk of heart disease and colon-rectal cancer, weight management, energy build-up and enhanced endurance [5-6]. In addition, this research showed that more than one motivating factor is needed for the majority of respondents to participate in physical activity. Researchers have given the inherent factors of health and wellness, enthusiasm and excitement, skills and experience, along with the organism concerned, five considerations. Researchers have identified four reasons for external factors: friends, family, university facilities and the university role.

\section{Research Background}

Most university students, men and women were indicated to be dissatisfied with their physical appearance [7]. Researchers find that girls are more likely than men to attain the ideal kind of body. Body weight and attractiveness are described for college students, as their sexual attractiveness can be improved. Physical exercise lets you have a slim or lean shape of your body and alleviate social discomfort.

Physical exercise in principle supports positive feelings like emotional distress, anxiety, stress, and low trust. Evidence indicates that exercise helps young people with low self-esteem build a positive self-image [8]. Participation of physical activity is often shielded by its impact on psychology from harmful social activities. In previous research various definitions of physical activity have been identified, and physical exercise is known to be the most effective method of treating the wellbeing of women [9]. It shows that women have a very important role in physical activity in preserving their physical health and form. Physical activity may be defined as the skeletal muscle's body movement and may minimise a person's calories [10]. This means that performing physical exercise will stay away from any harmful disease and that it is beneficial for one's health. Fitness may also offer health benefits for women and men. It has also been shown that the presence of physical activity reduces issues, increases healthy moral growth and enhances encouragement overall quality of life. Normally, purpose of women's and men's exercise is to provide health protection and help avoid dangerous diseases.

The position of individual motivation was the key issue of physical exercise and students' participation in physical exercise [11]. This suggests that physical activity motivation and participation are intertwined. Inspiration, personality, the atmosphere, fun, interest, friends, and family are all factors that encourage people to participate in physical activity [12-13]. Activities are often defined as recreational activities that must include freedom of choice, free motivation, relaxation and participation and self-expression [14]. Teenagers are becoming more mindful of the importance of physical activity in maintaining good health.

Moreover, a range of experience and activities will inspire UTeM students. Parenting is an integral aspect of young people's sports. Parents should however understand why children want to participate in sports activities [15]. This shows that parents of young men and women are frequently interested in physical activity in contrast with non-parents. The study concluded that students are more likely to perform sports as a family history and social circumstances around them and engage in physical activity.

The inspiration of the various realms is clearly supported by the fact that youth engage in sports because their friends and family support them in a very high manner [16]. Parents should learn how to engage in physical activity by training their children. Take children every weekend, for instance, for recreation and physical activity. Physical exercise ought to be enjoyable, so don't waste time. Physical exercise is also one of the key methods of ensuring an individual is involved. Participation of physical activity by students can help to improve everyone's happiness while also encouraging good health. However, the majority of people in developing countries do not adequately participate in healthy culture, considering the many health benefits of everyday exercise.

According to the previous study, women require moderate-intensity activities if the activity is connected to sports, leisure events, or household activities, and men engage in activities of high intensity. Researchers believe that in order to have better cultural activities, youth and students need a high-intensity experience that was meant to exist in their lives.

Based on a qualitative study of physical activity among teen minority adolescents in China and the Philippines, most Filipino teenagers favour moderate physical activity and do not use more energy than Chinese teenagers [17]. Based on this statement, it can be tried to argue that some habits, based on experiences in their daily lives, can be categorised as low, medium and high physical activity.

Rising teenage obesity rates are a global concern for public health. It not only influences the health of children and teenagers, but also increases the risk of obesity in adults. The reduction in physical activity contributes to health issues is widely believed [18]. Physical exercise is regarded as highly beneficial and effective health care for 
healthier and energetic adolescents.

Physical activity encourages confidence and a healthy lifestyle. The most effective way to minimise the chances of having non communicable disease is to exercise regularly, which proves both male and female students do physical activity in order to prevent health issues and lead a healthy lifestyle. Physical activity in turn benefits children and adolescents for their physiological and psychological well-being and has a significant role to play in producing and maintaining a pattern of health-related behaviour that continues in adulthood [19]. A child may have been exposed to physical activity and may continue to engage in physical activity as they grow older. It will keep you in good health.

Obesity in children in the United States has increased significantly, especially among non-physically active female [20]. Since they have no balanced culture or unusual eating patterns, 36.7\% of American girls between six and eleven are at risk of overweight. This means that all households should be introduced to a safe environment in order to train their children on physical exercise benefits.

Furthermore, the physical activity of students is very limited. The objectives of this research are to examine the effects of both intrinsic and extrinsic factors the physical activity of the students of Universiti Teknikal Malaysia Melaka (UTeM). Physical participation has shown to enhance the health and self-assurance of an individual. Physical exercise can also allow a student to be fit and secure during classroom work [21]. There are presently so many practises in order to shape an entire person, mentally, emotionally, socially or spiritually. Regular exercise or sport is one area that can make people useful. The exercise is of various kinds. These include jogging, walking, cycling, aerobics, kayaking, hiking, etc. Physical activity will give the younger generation a sense of goodwill and national integration. Initial training in management, character and community will also cultivate and nurture the physical activity of the younger generation.

This study analyses the factors behind motivation, the factors behind extrinsic motivation and the influence of participation in physical activity based on gender. Therefore, the research issues addressed are included in this study:

a) Is there a substantial difference in the fundamental motives of students to engage in gender-based physical activity?

b) Do gender physical activities have a substantial difference between the extrinsic motives of students?

This study's main aim was to examine the intrinsic and external motivational factors affecting the participation in physical activity by UTeM students. The research is also intended to classify the factors that are intrinsic and extrinsic to motivate students of UTeM to become involved in physical activity the most. Finally, this research explores how intrinsic motivation and external motivation affect the participation of UTeM students in physical activity.

\section{Methodology}

\section{Research Design}

This is a descriptive summary analysis. This research was a quantitative trial that started with data collection, analysis of the data, and findings, using digital data during the review process [22-32]. A data collection questionnaire was used to pick the survey template for this study. Data were collected using quantitative methods using modified and validated questionnaires to be correct.

\section{Participants}

A sample of 440 students selected from the different UTeM's curricula included in the main campus in Durian Tunggal, Melaka, where the respondents had to answer the questionnaire given in their class [33]. The participants are randomly made up of boys and girls in each of the different UTeM courses.

\section{Data Collection Procedure}

The researchers prepared questionnaires that was adapted from the Exercise Reward Inventory and Participation Motivation Questionnaire to collect data for this analysis [34-35]. The questionnaire was updated to make it easier for students to understand the questionnaire and to carry out appropriate study. The aim of this survey is to determine the degree to which motivational factors and associations with students' participation in physical activity are involved. The survey respondents' evaluations are based on a 5-point Likert scale. To ensure that the data gathered is in line with the objectives to be met, the preparation and selection methodology should be carried out with care and diligence.

\section{Data Analysis}

Analytical data obtained by descriptive and inferential statistics were analysed. The demographic study context and the basic variable factor are clarified using descriptive analysis. Researchers may answer study questions about their variations and associations between variables using separate t-test samples and multiple regression analysis (gender) [27-32].

\section{Results}

The four functional components of inner motivation are shown in Table 1: health and strength, energy and enthusiasm, skill and knowledge, and related bodies. In separate samples, the participation of boys and girls in health and fitness reward factors $(t=-0.05, \mathrm{p} 0.05)$ and body-related factors $(\mathrm{t}=-6.51, \mathrm{p} 0.05)$ was found to be substantially different. 
As shown in Table 2, extrinsic motivation is divided into four components: family, friends, sports, and our university facilities. Male and female student participation in family factors was found to be substantially different $(t=-6.98$, $p$ $0.05)$ in a review of independent t-test samples. Male $(\mathrm{M}=$ 3.52) and female $(M=4.09)$, on the other hand, the average family extrinsic motivation factor was higher. Min applies to the experiences of female students who are more motivated and inspired by extrinsic factors to participate in physical activity for their families.

Table 3 provides an overview of the effect of gaps in the involvement of UTeM students in gender-based physical activities. T-test review showed no substantial variations in the gender-based effect of the presence of UKMs ( $t=-4.20$, $p>0.05$ ). These findings show that gender has no impact on UTeM students' participation. Female students, on the other hand, had a higher mean participation rate $(\mathrm{M}=4.13)$ than male students $(M=3.92)$.

Table 1. Difference measure between students' inner incentive to conduct physical exercise on the basis of gender

\begin{tabular}{|c|c|c|c|c|c|c|c|}
\hline Motive & Gender & $\mathrm{N}$ & Mean & SD & $\mathrm{df}$ & $\mathrm{t}$ value & P Value \\
\hline \multirow{2}{*}{ Health and Fitness } & Male & 220 & 4.20 & 0.78 & 398 & -5.05 & 0.00 \\
\hline & Female & 220 & 4.53 & 0.50 & & & \\
\hline \multirow{2}{*}{ Interest and Enjoyment } & Male & 220 & 4.06 & 0.72 & 398 & -4.22 & 0.09 \\
\hline & Female & 220 & 4.33 & 0.55 & & & \\
\hline \multirow{2}{*}{ Skills and Expertise } & Male & 220 & 4.00 & 0.75 & 398 & -3.98 & 0.46 \\
\hline & Female & 220 & 4.29 & 0.69 & & & \\
\hline \multirow{2}{*}{ Bodies Related } & Male & 220 & 3.94 & 0.85 & 398 & -6.51 & 0.001 \\
\hline & Female & 220 & 4.42 & 0.60 & & & \\
\hline
\end{tabular}

Table 2. Examine gender disparities in students' extrinsic motives for physical activity

\begin{tabular}{|c|c|c|c|c|c|c|c|}
\hline Motive & Gender & $\mathrm{N}$ & Mean & SD & df & $\mathrm{t}$ value & P Value \\
\hline \multirow{2}{*}{ Family } & Male & 220 & 3.52 & 0.85 & 398 & -6.98 & 0.01 \\
\hline & Female & 220 & 4.09 & 0.77 & & & \\
\hline \multirow{2}{*}{ Friends } & Male & 220 & 3.79 & 0.71 & 398 & -4.89 & 0.111 \\
\hline & Female & 220 & 4.14 & 0.72 & & & \\
\hline \multirow{2}{*}{ Sports Facilities } & Male & 220 & 3.59 & 0.63 & 398 & -5.11 & 0.114 \\
\hline & Female & 220 & 3.97 & 0.60 & & & \\
\hline \multirow{2}{*}{ University Roles } & Male & 220 & 3.68 & 0.86 & 398 & -4.99 & 0.06 \\
\hline & Female & 220 & 4.09 & 0.76 & & & \\
\hline
\end{tabular}

Table 3. Test discrepancies between the effects of student participation in gender-based physical activities

\begin{tabular}{|c|c|c|c|c|}
\hline $\begin{array}{c}\text { Variables: Intrinsic Motivation } \\
\text { Factor }\end{array}$ & Coefficient $\left(\mathrm{R}^{2}\right)$ & t value & P Value & F Value \\
\hline Family & 0.19 & 1.38 & 0.14 & 65.59 \\
\hline Friends & 0.34 & 11.7 & $0.01^{* *}$ & $(0.00)$ \\
\hline Sports Facility & 0.38 & 3.70 & $0.04^{* *}$ & \\
\hline University Roles & 0.40 & 3.57 & $0.01^{* *}$ & \\
\hline
\end{tabular}

Table 4. The element that most contributed to the impact of UTeM students engaging in physical activity was intrinsic motivation

\begin{tabular}{|c|c|c|c|c|c|c|c|}
\hline Motive & Gender & $\mathrm{N}$ & Mean & $\mathrm{SD}$ & $\mathrm{df}$ & $\mathrm{t}$ value & $\mathrm{P}$ Value \\
\hline
\end{tabular}




\begin{tabular}{|c|c|c|c|c|c|c|c|}
\hline \multirow{2}{*}{ Impact of Involvement } & Male & 220 & 3.92 & 0.54 & 398 & -4.20 & 0.21 \\
\cline { 2 - 9 } & Female & 220 & 4.13 & 0.46 & & & \\
\hline
\end{tabular}

Table 5. Extrinsic incentive factor that most contributed to the effect of UTEM student engagement in physical activity

\begin{tabular}{|c|c|c|c|c|}
\hline Variables: Intrinsic Motivation Factor & Coefficient $\left(\mathrm{R}^{2}\right)$ & $\mathrm{t}$ value & P Value & F Value \\
\hline Health \& Fitness & 0.18 & -4.28 & $0.01^{* *}$ & 107.27 \\
\hline Interest and Enjoyment & 0.35 & 6.68 & $0.01^{* *}$ & $(0.00)$ \\
\hline Skills and Expertise & 0.44 & 5.55 & $0.04^{* *}$ & \\
\hline Bodies Related & 0.52 & 8.09 & $0.01^{* *}$ & \\
\hline
\end{tabular}

In a multiple regression analysis, Table 4 shows the consequences of the presence of UTeM in physical activity. Multiple regression tests have been used to test the variables most contributing to the impact of UTeM's physical students such as fitness and wellbeing factor, interest and pleasure factors, capacities and perceptions as well as corporal factors. The result indicates that intrinsic body-related motivating factors (52\%) are considered as the most important factor in the physical activity of UTeMs students.

Table 5 demonstrates the effects of the physical active effect of UTeM participation from a multiple regression analysis. In order to determine the extrinsic factor of motivation which contributed to the effect of participation of UTeM students in physical activities, several regression methods have been used for this problem. The students of UTeMs have conducted multiple regression analyses to see the effects of family, colleagues, sport and the role of the university in physical activity.

The study shows, in particular, that the universities' position in extrinsic motivation (40\%) is seen as the reason why the UTeM students' involvement in physical activity has played the greatest role.

\section{Discussion}

The discrepancy between study variables dependent on the philosophical meaning is indicated in the descriptive analysis and the effects of the mathematical inference.

The study's first question is that gender influences UTeM students' natural desire to engage in physical activity. The gender-driven physical activity of the UTeM student motivation component was tested with different samples of the t-test.

A t-test analysis of the various samples found a significant difference in the participation of males and females in health and exercise reward factors $(t=-0.05$, $p$ $0.05)$ and body-related factors $(\mathrm{t}=-6.51$, $\mathrm{p}$ 0.05).

In the meantime, male $(\mathrm{M}=4.20)$ and female $(\mathrm{M}=4.53)$ students have medium underlying health and fitness drivers. With equal body variables, male students $(M=3.94)$ and female students $(M=4.42)$ have the same mean. Woman students, on average because they are more concerned with their personal looks and health, are more inspired and affected by exercise or nutrition than male students. Previous research has shown that exercise and physical activity will assist in the recovery of cancer-stricken women [36].

This ensures that students, men and women, who engage in physical exercise, will maintain their health and avoid diseases that are harmful to their bodies. UTeM students are generally worried with their appearance, which is often appealing to those around them. Desire and pleasure, as well as skills and abilities, became main guiding forces, and there was no significant gender difference.

The second research issue is whether gender influences UTeM students' extrinsic motivation to engage in physical activity. Extrinsic motivation factors of UTeM students in gender-based physical activities were contrasted to see if they varied, is the main reason independent samples of the t-test were used. Male and female students were found to be significantly different in their participation in family variables ( $\mathrm{t}=-6.98, \mathrm{p} 0.05)$ in a study of independent t-test samples. In the meanwhile, for males $(M=3.52)$ and female ( $M=4.09$ ) households, there is an average element of extrinsic encouragement.

In terms of motivation and early exposure, women are more inspired by physical activities and are more inspired by their relatives than male students. Because of their families' heritage and history of building a balanced community, family support helps the participating of student's exercise. Adolescent involvement in sports and physical activity is based on parental support and motivation. It suggests that students' families have provided them with early exposure to a healthy and involved culture. On the other hand, there was no substantial gender disparity in the partners' intrinsic motivation, the sports centre, or the position of universities [36, 37].

The third research question is whether gender has an effect on UTeM students' physical activity participation. T-test research reported no major differences in the gender-based impact of UTeM presence $(\mathrm{t}=-4.20$, $\mathrm{p}>$ 0.05). These findings indicate that gender has no bearing on the effects of UTeM students' participation. Female students, on the other hand, had a higher mean participation rate $(M=4.13)$ than male students $(M=3.92)(38,39]$. 
The fourth research question is to define the fundamental motivation that inspires UTeM students to engage in physical activity. The multi-regression approach has been used to analyse the key driving factors relating to the physical activity effect of UTeM student attendance in this research. Multiple regression analysis was used to analyse the variables that add more to the influences of UTeM physically active students such as fitness and wellbeing factors, variables of attraction and pleasure, capability and experience and body-related factors. The analysis found that body-related intrinsic motivating factors (52\%) are considered to be the most important factors that have led to the effects of UTeM students in physical activities aligned with the prior study $(35,39]$.

Female students, on the whole, are more likely to participate in physical activity than male students. This is because they want to keep their bodies looking good and healthy [37]. This illustrates that individuals participating in physical activity and sport will benefit from maintaining a healthy and balanced body. Motivational competence and comprehension (44\%), motivational aspects of attraction and fun (35\%), and the motivational component of health and wellbeing (18\%) all tended to have an effect on UTeM's dedication to physical exercise. Curiosity, enthusiasm, and cognition appear to be one of the most significant factors influencing an individual's physical activity, according to these results.

Extrinsic motivation is also addressed in the fifth research issue, which is most applicable to the impact of UTeM students engaging in physical activity. The Multiple Regression Approach is used to examine the extrinsic motivating factor that had the greatest impact on UTeM students' physical activity participation. Multiple regression analysis was used to decide what variables, such as family, friends, sports motivation, and the position of our university facilities, affect UTeM students' physical activity participation.

The role of universities in the field of extrinsic motivation (40\%) is considered to be the factor most influential for UTeM students in physical activity, according to the report. This is analogous to the principle of the performance motivation, which states that the motivation of an individual is born and is promoted in a favourable setting [38].

Environmental factors, especially during training, play a significant role in determining motivation levels. Sports facilities' extrinsic motivation (38\%) and mates' extrinsic motivation (34\%), on the other hand, have been seen as leading to the impact of UTeM students engaging in physical activity. The motivation factor, on the other hand, is not significant in determining the impact of students' physical activity participation.

\section{Conclusions}

All and all, physical education is a means of maintaining a healthy lifestyle for UTeM students. In terms of both intrusive and extrinsic influences, UTeM students' involvement in physical activity is affected by a variety of factors. This is backed by the theory that university-aged boys and girls are acutely conscious of their bodies and view other mates as a result of their bodies' attraction to the opposite sex.

In short, the study showed that the majority of students believe UTeM incentive pushes students into physical exercise with corporal factors (intrinsic factors) and university status, inherently and externally (extrinsic factors). This demonstrates that UTeM students are motivated to engage in physical activity in order to retain the University's knowledge and help in all areas.

According to the achievement motivation theory, a person is born with the ability to improve if their surroundings are favourable. Environmental factors, particularly during an exercise, have a significant impact on a student's motivation. The research also found a connection between intrinsic motivators and the effect of UTeM student attendance on physical activity. This means that fundamental motivators like health and wellbeing, passion and excitement, ability and knowledge, as well as associated bodies, have a huge influence on students' involvement in physical activity.

Extrinsic motivational influences, on the other hand, often contribute to students' engagement, even if they have a minor impact. As a result, any community comprising of the UTeM and the University's Sports Department should emphasise the motivational aspect of encouraging more students to participate in physical activity, thus promoting healthy cultural activities for both male and female students

This research is also important for the physical and spiritual growth of students. This practise shows that inspiring students to live more active lives is the most powerful way to make the next generation healthier and more energetic.

\section{Acknowledgements}

Authors are grateful to Faculty of Education, Universiti Kebangsaan Malaysia that had funded this study via an internal research grant (Code No.: GG-2019-079).

\section{REFERENCES}

[1] Hanlon C, Morris T, Nabbs S. Establishing a successful physical activity program to recruit and retain women. Sport Management Review, 2010, 13(3):269-282.

[2] Landers D M, Arent S M. Physical activity and mental health. Handbook of Sport Psychology, 2001, 2:740-765.

[3] Ainsworth B E. Issues in the assessment of physical activity in women. Research Quarterly for Exercise and Sport, 2000, 
71(sup2):37-42.

[4] Nelson M E, Rejeski W J, Blair S N, Duncan P W, Judge J O, King A C, Macera C A, Castaneda-Sceppa C. Physical activity and public health in older adults: Recommendation from the American College of Sports Medicine and the American Heart Association. Circulation, 2007, 116(9):1094-1105.

[5] MacKelvie K J, Khan K M, Petit M A, Janssen P A, McKay $\mathrm{H}$ A. A school-based exercise intervention elicits substantial bone health benefits: A 2-year randomized controlled trial in girls. Pediatrics, 2003, 112(6):e447-e452.

[6] Razak, M. R. A., Ismail, E., Bakar, A. Y. A. Profiling of physical activity, health fitness (VO2max), body composition, and dietary intake among Malaysian university students: A case study. International Journal of Human Movement and Sports Sciences, 2020, 8(6): 413-420.

[7] Muth J L, Cash T F. Bodyimage attitudes: What difference does gender make? Journal of Applied Social Psychology, 1997, 27(16):1438-1452.

[8] Taliaferro L A, Rienzo B A, Pigg R M, Miller M D, Dodd V $\mathrm{J}$. Associations between physical activity and reduced rates of hopelessness, depression, and suicidal behavior among college students. Journal of American College Health, 2009, 57(4):427-436.

[9] Chodzko-Zajko W J, Proctor D N, Singh M A, Minson C T, Nigg C R, Salem G J, Skinner J S. Exercise and physical activity for older adults. Medicine and Science in Sports and Exercise, 2009, 41(7):1510-1530.

[10] Caspersen C J, Powell K E, Christenson G M. Physical activity, exercise, and physical fitness: Definitions and distinctions for health-related research. Public Health Reports, 1985, 100(2):126-131.

[11] Kilpatrick M, Hebert E, Bartholomew J. College students' motivation for physical activity: Differentiating men's and women's motives for sport participation and exercise, Journal of American College Health, 2005, 54(2):87-94.

[12] Nazarudin M N, Noordin H, Suppiah P K, Abdullah M R, Fauzee M S, Abdullah N M. Psychological skills assessment and referee rugby sevens performance. Jurnal Pemikir Pendidikan, 2014, 5:165-184.

[13] Nazarudin M N, Abdullah M R, Fauzee M S, Zainuddin Z A. Developing a decision-making test for rugby referees. Malaysian Journal of Sports, Recreational and Education, 2015, 2(1):77-85.

[14] Haskell W L, Blair S N, Hill J O. Physical activity: Health outcomes and importance for public health policy. Preventive Medicine, 2009, 49(4):280-282.

[15] Brustad R J. Attraction to physical activity in urban schoolchildren: Parental socialization and gender influences. Research Quarterly for Exercise and Sport, 1996, 67(3):316-323.

[16] Pichardo D A. What motivates young Latina females along the US Mexico border region to participate in team sports? Master thesis, Texas: The University of Texas at El Paso, 2010.

[17] Wing Kwan M Y, Bray S R, Martin Ginis K A. Predicting physical activity of first-year university students: An application of the theory of planned behavior. Journal of American College Health, 2009, 58(1):45-55.

[18] King A C, Castro C, Wilcox S, Eyler A A, Sallis J F, Brownson R C. Personal and environmental factors associated with physical inactivity among different racial-Ethnic groups of US middle-aged and older-aged women. Health Psychology, 2000, 19(4):354-364

[19] Lewis N, Dollman J, Dale M. Trends in physical activity behaviours and attitudes among South Australian youth between 1985 and 2004. Journal of Science and Medicine in Sport, 2007, 10(6):418-427.

[20] Kin-Isler A, Asci F H, Altintas A, Guven-Karaban B. Physical activity levels and patterns of 11-14 years old Turkish adolescents. Adolescence, 2009, 44(176):1005-101 5.

[21] Segar M L, Eccles J S, Richardson C R. Type of physical activity goal influences participation in healthy midlife women. Women's Health Issues, 2008, 18(4):281-291.

[22] Gordon-Larsen P, Griffiths P, Bentley M E, Ward D S, Kelsey K, Shields K, Ammerman A. Barriers to physical activity: Qualitative data on caregiver-daughter perceptions and practices. American Journal of Preventive Medicine, 2004, 27(3):218-223.

[23] Al-Odaini N A, Zakaria M P, Zali M A, Juahir H, Yaziz M I, Surif S. Application of chemometrics in understanding the spatial distribution of human pharmaceuticals in surface water. Environmental Monitoring and Assessment, 2012, 184(11):6735-6748.

[24] Juahir H, Zain S M, Aris A Z, Yusof M K, Samah M A, Mokhtar M. Hydrological trend analysis due to land use changes at Langat River Basin. Environment Asia, 2010, 3:20-31.

[25] Mun'im M H N, Latif M T, Othman M, Dominick D, Mohamad N, Juahir H, Tahir N M. Composition of selected heavy metals in road dust from Kuala Lumpur City Centre. Environmental Earth Sciences, 2014, 72(3):849-859.

[26] Aris A Z, Abdullah M H, Praveena S M, Yusoff M K, Juahir $\mathrm{H}$. Extenuation of saline solutes in shallow aquifer of a small tropical island: A case study of Manukan Island, NorthBorneo. Environment Asia, 2010, 3(Special issue):84-92.

[27] Toriman M E, Gasim M B, Yusop Z, Shahid I, Mastura S S Abdullah P, Jaafar M, Aziz N A, Kamarudin M K, Jaafar O, Karim O. Use of 137 Cs activity to investigate sediment movement and transport modeling in river coastal environment. American Journal of Environmental Sciences, 2012, 8(4):417-423.

[28] Abdullah M R, Maliki A B H M, Musa R M, Kosni N A, Juahir H, Mohamed S B. Identification and comparative analysis of essential performance indicators in two levels of soccer expertise. International Journal on Advanced Science, Engineering and Information Technology, 2017, 7(1):305-314.

[29] Abdullah M R, Maliki A B H M, Musa R M, Kosni N A, Juahir H, Haque M. Multi-hierarchical pattern recognition of athlete's relative performance as a criterion for predicting potential athletes. Journal of Young Pharmacists, 2016, 8(4):463-470. 
[30] Abdullah M R, Eswaramoorthi V, Musa R M, Maliki A B H M, Kosni N A, Haque M. The effectiveness of aerobic exercises at difference intensities of managing blood pressure in essential hypertensive information technology officers. Journal of Young Pharmacists, 2016, 8(4):483-486.

[31] Abdullah M R, Musa R M, Maliki A B H M, Kosni N A, Suppiah P K. Development of tablet application based notational analysis system and the establishment of its reliability in soccer. Journal of Physical Education and Sport, 2016, 16(3):951-956.

[32] Musa R M, Abdullah M R, Maliki A B H M, Kosni N A, Haque $\mathrm{M}$. The application of principal components analysis to recognize essential physical fitness components among youth development archers of Terengganu, Malaysia. Indian Journal of Science and Technology, 2016, 9(44):1-6.

[33] Abdullah M R, Kosni N A, Eswaramoorthi V, Maliki A B H M, Musa R M. Reliability of test of performance strategies-competition scale (TOPS-CS) among youth athletes: A preliminary study in Malaysia. Man India, 2016, 96(12):5199-5207.

[34] Markland D, Hardy L. The exercise motivations inventory: Preliminary development and validity of a measure of individuals' reasons for participation in regular physical exercise. Personality and Individual Differences, 1993, 15(3):289-296.

[35] McCullagh P, Matzkanin K T, Shaw S D, Maldonado M. Motivation for participation in physical activity: A comparison of parent-child perceived competencies and participation motives. Pediatric Exercise Science, 1993, 5(3):224-233.

[36] Courneya K S, Mackey J R, Bell G J, Jones L W, Field C J, Fairey A S. Randomized controlled trial of exercise training in postmenopausal breast cancer survivors: Cardiopulmonary and quality of life outcomes. Journal of Clinical Oncology, 2003, (9):1660-1668.

[37] Bandura A. Social cognitive theory: An agentic perspective. Annual Review of Psychology, 2001, 52(1):1-26.

[38] McClelland D. C., Atkinson J. W., Clark R. A., Lowell E. L. The achievement motive. New York: Appleton Century-Croft, 1953.

[39] Olena Lutsenko, Gregory Lucenko, Maryna Khrolenko, Olesya Mehem , "Defining the Conditions of Forming Students Motivation to Movement Activity," International Journal of Human Movement and Sports Sciences, Vol. 8, No. 4, pp. 117 - 123, 2020. DOI: 10.13189/saj.2020.080403. 